\title{
Sexual Acting Out As an Abortive Mourning Process in Female Adolescent Impatients
}

The development of psychologically healthy means for coping with sexuality is particularly diffcult for disturbed adolescents who need residential treatment. One of the clearly definable psychodynamic constellations that underlie sexual acting-out-an abortive mourning process in response to separations or losses suffered by female adolescent inpatients-is discussed. John Bowlby's theory of the mounning process is emphasized in understanding the immediate reaction to loss.

Case material is presented in support of the hypothesis that with some disturbed female adolescents, heterosexual acting-out wards off a regressive wish, kindled by object loss, to rewnite symbiotically with the preoedipal mother. Suggestions are given for milieu management and psychotherapy in such cases.

Adults who care for adolescents face the gargantuan task of helping them to modulate and direct intense aggressive and sexual impulses. Harried parents must cope with a child who sometimes appears ungovernable. The situation is magnified on an adolescent psychiatric ward where, emotionally crippled by immature egos, disturbed adolescents are continuously in danger of losing control of their impulses and feelings. Such adolescents are unusually prone to use sexual behavior to alleviate or cover over tension. The treatment of disturbed adolescents involves fostering a capacity for aim-inhibited discharge of sexual impulses:

The authors are instruetors in psychiatry at the University of Michigan Medical Center, Ann Arbor, Michigan 48104. 
an ability to enter into intimate relationships in which sexual release leads to enrichment of the relationship. In promoting this treatment goal, it is important to investigate both the viscissitudes of sexual development in adolescence, as well as ways in which sexuality serves to camouflage other conflicts.

Adolescents' preoceupation with sex and sexuality involves mastery of such developmental tasks as mapping out body boundaries, control of pregenital and genital impulses, consolidation of sexual indentity, and binding of sexual and loving yearnings to age-appropriate objects. There is little consensus on the best approach for helping adolescents to oope with their sexuality. ${ }^{1}$ Adults react to adolescent sexuality with great ambivalence, particularly in girls. They wish to shield pubertal girls from the dangers to body and spirit of unleashed sexual drives. On an adolescent inpatient ward, professionals faced with the crunch of dealing with age-appropriate dating by their female adolescent charges behave like nervous parents, in a twitter about the fate of their female child's chastity and innocence. ${ }^{2}$ Those responsible for the clinical management of disturbed adolescents need consistent values and a flexible set of rules which they truly believe in regarding sexual activity. This bulwark of values and rules fosters identity consolidation and disengagement from childish parental ties. The adolescent develops an increasing sense of integrity through repeated jousts with his adult protectors. These institutional rules and values, however, also provide a secure haven when inner drives or the demands of the opposite sex become too pressing. The adolescent may complain unceasingly about tyrannical rules, but appreciates as well their protection. ${ }^{3}$

When an adolescent ward is staffed by young people not long out of adolescence themselves, the need to enforce and embody values felt by both patients and staff to be middle class and middle age promotes great inner strain in the staff. Young child care workers often are operating with an attitude toward adult values more similar to their charges than to the doctors with whom they work. On the ward to be described the young staff were intensely ambivalent about enforcing the milieu's rules, because these rules were experienced as "adult" values of the therapists and consequently threatened to foreclose prematurely their own search for values and identities. This struggle sometimes blinded them to the significant therapeutic implications of confronting 
disturbed children in parental fashion over such issues as the latters' laxness in taking care of themselves and their environment. ${ }^{4}$

In early and middle adolescence, with the turmoil of puberty only recently subsided, sexuality is prominent on all developmental fronts. It is consequently striking that so little has been written that systematically deals with the elinical management of the sexual behavior of inpatient adolescents. ${ }^{1,5}$ In understanding this behavior, there has been heavy emphasis on the regressive contamination of sexual impulses by aggression., ${ }^{1,6}$ Easson $^{5}$ noted how their sexual and romantic attachments quickly metamorphose into regressive symbiotic ties, which become rich cultures for the acting out of needs, conflicts and anxieties. Levy, ${ }^{2,7}$ more directly addressing the management issue, illustrated how easily staff on an adolescent unit can lose therapeutic objectivity in worrying about a girl "ruining herself" through sexual acting out. This literature provides some very general guidelines for the clinical management of sexual acting-out among adolescents, but nowhere does it discuss in depth any psychodynamic syndromes connected with this sort of behavior.

This paper will explore one constellation of conflicts that results in sexual acting-out among disturbed female adolescents, some of whom have foundered on the developmental task of separation-individuation ${ }^{8,9}$ and others who have suffered breakdowns in their family structure which have led to severe characterological difficulties. It is assumed that there are definable psychodynamic constellations that underlie sexual acting-out. Sophisticated clinical management demands a clearer understanding of these syndromes. Lacking a dynamic framework staffs' responses to sexual behavior buffet them back and forth along a repressive-permissive continuum or lock them rigidly onto one point. Furthermore, without such a dynamic orientation staff are vulnerable to excessive preoccupation with the sexual behavior itself, thereby losing sight of the full range of affective communications involved. ${ }^{2}$

\section{The Trauma of Hospitalization}

Clinical examples will be presented in which sexual or pseudoromantic acting-out was a response of several troubled adolescents to an emotional crisis sparked by specific interpersonal and intra- 
psychic conditions. These examples come from the inpatient ward of a major university teaching hospital. This ward has a maximum census of 10 girls and 10 boys, along with room for several day care patients. The treatment approach is a psychoanalyticallyoriented integration of milieu, counseling groups and individual psychotherapy. The therapeutic program for each patient is formulated and implemented by a treatment team including ward staff (e.g., child care workers, teachers) and coordinated by the patient's therapist, usually a psychiatric resident.

An adolescent admitted to the service is subjected to the painful, often traumatic, experience of being separated from family and home. He is unable to comfortably weather the stress of removal from family life-no matter how pathogenic the family. The adolescent also is vulnerable to future separations and losses in the hospital: Therapists rotate through the service; young staff rarely stay for more than a year or two; and all staff inevitably take vacations. Though the patients stay for no more than a year or two at the most, they often have to cope with the loss of people whom they have come to like and value.

It was observed that female patients frequently react to the separation or loss of a valued object by attempting to initiate a sexual relationship with a male patient. If the separation is temporary (e.g., therapist or staff vacation), such a relationship is initiated in the absence of any conscious anger or anxiety about the separation. When the loss is permanent, as when a therapist or staff member leaves the service, there is no overt indication that a healthy mourning process is underway: There is little indication of any conscious grief, despair, and anger..$^{10-13}$

These phenomena suggest that this sexual acting-out may be a manifestation of an abortive mourning process. In their consultation to a Juvenile Court, Shoor and Speed $^{14}$ postulated a similar connection, based on their observations of sexual promiscuity in female adolescents who recently had suffered the death of a relative. However, their analysis was limited to the formulation that sexual acting-out represented the "pathological masking of grief."

The losses referred to here do not necessarily involve the object's actual death, although these objects may be permanently separated from the patient. Adolescents can face several different kinds of losis : 
(1) The normative separation-individuation process of this age requires giving up old patterns of relationships. The objects continue to exist in actuality, but the infantile form of the relationship is abandoned. ${ }^{11,15}$

(2) Death of course necessitates giving up the relationship as well as all possibilities for future contact with the object.

(3) While relationships often end and the object exists somewhere, it may never again be seen.

The losses described in this paper fell in the last category. It may be that such partial losses involve processes somewhat different from those of mourning of the dead. The contention here is that this sort of loss activates certain components of the full mourning process. ${ }^{12}$

It is helpful in understanding the disturbed adolescent's response to separation to consider how much the normal adolescent search for autonomy resembles the loss and mourning process. The normal separation-individuation task of adolescence in many respects parallels the mourning process. It is an adaptational task serving to free the individual from objects and/or patterns of relationships that no longer are available; and if the process runs smoothly, the ego is enriched as a result. ${ }^{8,10-12,15,16}$ Throughout this period, however, the adolescent is vulnerable to anxiety and depression associated with the threat of ego improverishment or, of greater terror, self-dissolution. This vulnerability stems from the adolescent's poorly consolidated identity and character structure, leaving him with few enduring internal moorings in the face of loss of comforting inner object relationships. When faced with such fears, the adolescent is prone to make a "forceful turn" to the outside world through peer and extra-parental relationships, in order to reaffirm ego-integrity through action, physical contact, intense relationships and identifications with adults. In other words, intense involvement with peers is a common vehicle for adolescents to act out their conflicts, particularly a sense of inner loss. ${ }^{8,15}$

\section{Abortive Mourning Reactions}

Bowlby's ${ }^{13,17}$ conceptualization of three stages of mourning provides a useful framework for understanding how disturbed adolescents cope with separation and loss. Particularly relevant is 
his first stage, "protest," in which the individual frantically and angrily seeks to regain the lost object, not admitting to the possibility that it is lost forever. Bowlby states that fixation at the first stage is an inevitable byproduct of childhood loss, setting the stage for pathological reactions to separation or loss in later years.

These reactions are characterized by a profound ego split, in which the occurrence of a loss is consciously accepted but its irreversibility is denied. There may be some overt grief and anger in reaction to the loss, along with considerable anxiety. When these feelings are no longer noticeable it is not due to resignation to the loss; rather, the grieving, anxious search to regain the lost-now idealized-object and the bitter reproaches toward all held responsible for it become woven into the character structure, leading to much unhappiness. Often individuals whose characters are warped in this way tend repetitiously to become involved in self-destructive romantic relationships in which only their own fantasied omnipotence promises to make all turn out happily, thus undoing the original loss..$^{14,18-20}$

\section{Reactions to Separation and Loss in the Disturbed Adolescent}

The adolescent finds it difficult to relinquish affective ties to a lost object, because of the fear of ego confusion and impoverishment. He must cope with the press of a confusing array of strong impulses, without consolidated character structure or defenses to serve as regulators or controls. The adolescent looks to external objects as comforting anchor points to help him weather his feelings of floundering in a sea of emotional chaos, and to counter his sense of loneliness.

For the disturbed adolescent, hampered further by immature ego and drive organizations, interpersonal relationships serve essential need-gratifying functions. When external objects provide narcissistic sustenance to the ego, without which its integrity is lost, then the loss of objects threatens more than ego impoverishment-the very preservation of the self is endangered. For these adolescents self-esteem is regulated primarily through an (at least fantasied) attachment to an idealized object: He shares in the object's goodness and power. If the object's departure were to be seen as resulting from some weakness or deficiency in it, this would kindle in the adolescent feelings of disparagement 
and contempt. Were these feelings unleashed at the object, they would ultimately recoil upon the adolescent, because, in fact, sharing in the idealization of the former serves to ward off those very feelings to which the adolescent is vulnerable from harsh superego introjects.

In the face of a separation or loss the ego is felt as helpless and the departed object is seen as cruel and callous for having left, which in part serves to ward off any sense that it is weak. But while the adolescent steers clear of the Scylla of collapsed self-esteem, he still is faced with the Charybdis of defused ambivalence, flooding the ego with unneutralized and narcissistic rage. ${ }^{19,20}$ This further intensifies the fear of ego- and self-disintegration.

At this point intense acting -out by a disturbed adolescent is likely, as he engages in a frantic search for recovery of the object. This search attempts to ward off a terrifying sense of frustration and helplessness through narcissistic re-engagement with the providing object, a relationship modeled on the attachment to the flowing breast. When an adequate external object is found, an illusory sense of weli-being may be reinstated. However, the basic attitude that the ego is incapable of autonomous, adaptive activity remains.

Acting-out in this kind of situation is ego syntonic and consequently is minimally available to therapeutic interpretation. ${ }^{21}$ Often, the best that can be done initially is to guide the adolescent in a direction where he is less likely to get hurt. A supporting net of therapeutic staff must be available to catch the distraught adolescent in his headlong plunge from inner terror. How difficult it can be at times for staff is illustrated in the following vignette:

Carol is an attractive 16-year-old, whose father had deserted the family when she was 8 years old. Subsequently, mother had transient impulseridden relationships with a succession of men, and as Carol grew older her mother would take her to bars to help attract men. Carol had difficulty establishing close relationships with anyone. The first and only close relationship she established on the ward was with Jack, an athletic male staff member. Carol's life revolved around this relationship; her moods and sense of self and the world were significantly influenced by the immediate state of her relationship with Jack. When Jack formally announced his intention to leave the unit, Carol reacted with sorrow. She 
then quickly became involved in a maudlin romance with one of the male patients, in which no sex was involved because they were going to "save themselves" for marriage. When Jack left, Carol immediately dropped her boyfriend. She tearfully pleaded to be discharged, loudly claiming that there was nothing left for her on the unit. Following a call from Jack and in the same week an informal written invitation to visit a young charismatic evangelist she had met, Carol ran away. It later was learned that she had unsuccessfully attempted to seek out and stay with the evangelist, and eventually had found her father with whom she previously had little contact. Throughout all of this, Carol was never able to utter an angry word about Jack, and was probably unaware of feeling angry at him.

It is evident that Carol felt Jack to be indispensible to her wellbeing, and was in many respects symbiotically attached to him. The fact that Jack was alive somewhere fueled both Carol's protest against the loss and her splitting of ambivalence. This resulted in her belief that she must regain Jack or someone like Jack to survive, and that none of the staff who remained could replace him. Carol's reaction to this loss paralleled the protest reaction of the first stage of mourning.

\section{Sexual Activity: Fuight from Pre-oedipal Tims}

Disturbed adolescent females often respond to object loss by acting out sexually. The adolescent girl usually gets involved with a male patient. One prime incentive for this is the search to regain a sense of well-being through possession of an object that provides narcissistic sustenance to the immature ego-a fantasied repossession of the good maternal breast. It is this wish that makes it so necessary for the grieving adolescent girl to seek a male.

The loss of a valued extra-parental object (or of parents) intensifies the adolescent's struggle with separation-individuation. Particularly in disturbed adolescent girls, a separation or loss intensifies the regressive wish for reunion with the pre-oedipal mother. This wish stirs up anxiety associated with merger fantasies and homosexual yearnings. 19, 22-24 The frantic search for a passionate involvement with a boy is provoked by the adolescent girl's terror of these wishes. Such an involvement serves to ward off this terror, while at the same time providing a vehicle for the symbolic gratification of regressive and progressive wishes. 


\section{Case Illustratrons}

Case 1. Marilyn is a tense, quiet 15-year-old whose parents were prone to violent and often physically assaultive quarrels, during which they would either threaten each other with mayhem or threaten suicide. When Marilyn was five, her parents divorced. Father remained dependent on the family, particularly on his ex-wife, for emotional support. As an adolescent, after experiencing several traumatic rejections by mother, Marilyn began using drugs, truanting and running away. On the ward she was prone to explosive and violent outbursts and successfully intimidated the other patients and many of the staff who worked most closely with her. She expressed feelings in short puffs like steam escaping from a pressure cooker.

After she had spent several months in the hospital, Marilyn's therapist decided to cut off all contact between the girl and her parents, and to make her a ward of the court. This was done because neither parent really wanted her. Furthermore, mother tormented Marilyn by alternately requesting her to come home one minute and refusing to have any reresponsibility for her the next. When the therapeutic team finally initiated this segregation of parents and patient, Marilyn made desperate attempts to contact her mother and with muted hatred accused her therapist of brainwashing her parents and separating them for his own cruel pleasure. It was during this time that Marilyn became involved in a passive exploitive relationship with a boy on the ward. Escalation of sexual acting-out was prevented only by prompt imposition of restrictions on both of them. However, she remained his patsy, tagging along after him and doing his bidding.

This relationship quickly petered out, but after a few months new circumstances promoted development of an even more intense pseudoromantic relationship. As a result of rotations of resident therapists through the service, Marilyn obtained her first female therapist. Shortly after this, contacts with Marilyn's parents, particularly her mother, were reinstituted. This occurred about the same time that plans were being made to transfer her to a residential treatment center for long-term placement. During this same period a female staff member with whom Marilyn had been very close left the unit. In sum, Marilyn's life was filled with important women coming and going. As well, she was anticipating her own imminent departure from the unit. Marilyn became involved with a male patient in an intense symbiotic and occasionally sexual relationship. For her part the vicissitudes of this relationship clearly reflected Marilyn's attitudes toward her therapist and female staff upon whom she relied. If Marilyn wanted to impress her therapist or staff with her maturity, she would temporarily withdraw from the relationship with the boy, Frank. If she felt angry at or disappointed in someone, the relationship with Frank 
would heat up. Frank was black and, interestingly, Marilyn, who had olive skin, thought at times that she was getting darker.

One night a female nurse atfempted to separate Frank and Marilyn, who were petting, and the latter violently struck the nurse. This and similar sexual and aggressive behavior involving the relationship with Frank was met with sharp curtailment of her interpersonal contacts. Indeed, she ended up spending a great deal of time with female staff. This sequence of events, beginning with the movement of women through her life, to the involvement with Frank, the consequent sexual and aggressive activity, and culminating in extensive contacts with female staff, may be viewed as an attempt by Marilyn to gain a close relationship with a mothering figure, while consciously denying it through her relationship with Frank. Furthermore, the simultaneous denial and symbolic gratification of regressive symbiotic and homosexual longings certainly was suggested by her fantasy that she was becoming darker like Frank.

Case 2. Diane is a cute, slight 15-year-old, whose parents had been dissolving their marriage for several years. This process started subsequent to the maternal grandfather's death, when Diane was 4 . He had functioned as a father for both of Diane's parents. Diane's maternal grandmother and mother both are dependent women, and her father, who had lost his father when he was a small child, emotionally regained him in the person of Diane's maternal grandfather. Subsequent to the grandfather's death, Diane's father had divided his time between a girl friend and the family. When father was present everyone was on best behavior for fear that if provoked he would irrevocably abandon them. He seemed to enjoy a playful, seductive yet emotionally distant relationship with Diane, his oldest daughter. Mother is a very insecure woman who experiences any disagreements with her children as personal criticisms, which depress and infuriate her. Father finally left the family, using as an excuse Diane's expressed concerns about the marital discord. It was shortly after this that Diane ingested a very large dose of aspirin and was hospitalized. On the ward she displayed a predilection for establishing playful, titillating and idealizing relationships with attractive male staff, and a demanding complaining relationship with her female ward manager, whom she called "Momma Harden."

Diane's struggles with the treatment recommendation for long-term placement in a more open residential setting are instructive. The recommendation was made several months before if would be implemented, the same period during which her parents' divorce would be finalized. It was hoped that during the period of reaction to the recommendation for placement and the parents' divorce proceedings, Diane could be helped to accept the disappointment of her wish for reunification of the family of her childhood: grandparents, father and mother. Helping her 
to mourn this loss would foster the normative separation-individuation process.

Following the recommendation to leave the unit and remain separated from her parents, Diane had a sudden upsurge of sexual play with male patients and verbalized sexual thoughts about her favorite male staff. Yet, she was spending less time with these male staff than with her female ward manager, of whom she angrily demanded to fix things up - "things" which remained unclarified. Diane also demanded to see more of her mother. Her anger at parents for rejecting and abandoning her surfaced with greater frequency and duration. The bitter reproachful attitude that mother was not worth enough to keep father in the family remained displaced onto her ward manager. Toward the mother she harbored the fantasy that mother would gather her children (three girls) around her and all would take care of each other in the absence of a man. Diane began having weekend passes alternately with mother and father. After one of these passes with mother and her sisters, she brought back a photo album and began reorganizing old photos of her family and relatives, including her grandparents. While doing this she sadly reminisced about good times past. Shortly after this she began to get alternately deeply depressed and intensely enraged. Her daily functioning collapsed, and she felt herself to be in "little pieces."

Diane began to feel intense sexual excitement in the presence of her favorite male ward staff, and let it be known in not too subtle ways that she was engrossed in sexual thoughts about them, as well as her father. In addition, she became aggressively titillating with male ward staff, taking sexy poses and rubbing up against them. Erotic fantasies about her therapist, while undoubtedly present, were kept in the background. She communicated her concerns about these fantasies to ward staff and to her therapist in such a way that everyone found themselves stepping on each other's toes trying to deal with this information in a sensitive, respectful manner. In the middle of all of this staff confusion and embarrassment, Diane began emotionally walling herself off, with the attitude that the staff upon whom she relied had turned out to be callous, treacherous and sexually hypocritical. In her therapy it was suggested to Diane that she was manufacturing this barrier of distrust to protect everyone from the rage pressing from within, and for self-protection from her painful sadness and longing. The mistrustful attitude, as well as the sexual excitement, quickly diminished, and she began relating to staff in a more differentiated manner. At the same time she angrily refused to see her parents "ever again."

The open, angry rejection of her parents for abandoning her was concurrent with a new desperate clinging to her favorite members of the staff, both male and female. Furthermore, her female ward manager, 
a highly competent and emotionally well-balanced woman, began to feel drained by the intensity and quality of Diane's demands upon her time and efforts. It was during this period that for the first time in her therapy Diane was able openly to share with her therapist the great sadness and longing for love which was tearing her apart emotionally. Her fury toward parents and rejection of them came to be fueled by the defensive need to protect herself from facing her wishes to be cuddled and loved by them.

The events of this period of her treatment more clearly than before revealed how her sexual activities toward male patients and staff, as well as her angry defiant attitudes, frequently served to ward off painful sadness and longing for love. That these feelings were associated with frightening regressive urges to regain a narcissistic, symbiotic union with mother was evident in the changing quality of Diane's relationship with her female ward manager during this period. Diane fluctuated between clinging avariciously to this woman and abruptly refusing to have anything to do with her.

\section{Protest of Loss in the Disturbed Adolescent}

A mourning-like reaction has been discussed which involves a profound emotional protest, catalyzed by the loss of a cherished relationship. Previously, this protest has been regarded as an attempt to regain the lost object. When in females it is expressed through embroilment in self-destructive heterosexual relationships, this protest has been viewed as an attempt to coerce the object's return through a show of distress. It is usually a lost father whose return is longed for. ${ }^{14,20}$ It is contended here, however, that frequently when disturbed adolescent girls sustain a loss or separation, it also activates the regressive wish to reunite with infantile objects, particularly the pre-oedipal mother.

Two factors need to be considered in this process. First, severe disturbance in adolescence very frequently rests on early disturbances in the mother-child relationship, accompanied by fixation at a narcissistic, symbiotic relationship with the mother. ${ }^{9}$ In the cases presented here mother and daughter always had been forced to rely on one another excessively, due to emotional, and often physical, abandonment by father. The treatment of these girls revealed that no matter how much they sought the company of males, they all emotionally clung to the conviction that survival depended upon a nurturant attachment to a woman. Secondly, no matter how pathogenic the family environment, when 
a child is removed from home to become an inpatient, the separation is likely to be experienced as a traumatic loss, an adandonment comparable to the death of the parents. It has been observed that soon after arrival on the adolescent service many patients have outbursts of intense rage, in which they must be closely supported and often physically held. It could be argued that such outbursts are the expression of a profound protest to being separated from parents (or parenting objects), for in spite of the pathology of these relationships, the parents remain the aim of intense regressive attachments.

\section{Clinical Management of Adolescent In-Pattent} Response to Loss

When a patient's sexual activity rings like an alarm throughout the ward community, then it is seldom an expression of growth and experimentation but, rather, intones the adolescent's desperation. It is at these times that a response based on thorough dynamic understanding is imperative.

When such behavior results from a reaction to separation or loss, the adolescent needs to be supported by a network of trusted and valued staff, who can serve as recipients of either aggressive or libidinal cathexes. Adolescents display a particular inability to tolerate the turning inward necessary to disengage from lost objects. They can emotionally let go of a lost object only if they feel that valued and supportive objects are immediately available to eathect. When this support isn't felt to be readily available, the adolescent may frantically search for the lost object, as was illustrated in Carol's case. ${ }^{18,20}$

It is unwise for a therapist and staff to rest once a patient has formed one close relationship with a staff member. Especially on adolescent units where there is relatively high staff turnover (e.g., units with younger staff, teaching hospitals), several ward staff members must be involved with the patient. When a patient has a relationship with only one staff member, this leaves her vulnerable to feeling cast adrift upon separation from that single valued object.

It is likely that staff will provide more effective support to an adolescent in a crisis of separation or loss if they have a clear understanding both of the psychic pain and growth-enhancing potential of such an experience. It is important, therefore, that 
ward staff be thoroughly educated about the psychological processes involved in adolescent reactions to separation and lossi.e., adolescent mourning. Furthermore, the arrangements both practical and emotional for the adolescent's discharge from a unit should be clearly articulated in the treatment program as soon as possible. It is not something that should wait for a last minute "working through of feelings"; rather, just as in a healthy family where parents begin as early as infancy preparing the child for adolescent separation-individuation, the treatment team from the outset should begin preparing themselves and their patient for eventual separation.

A separation or loss sustained by a disturbed adolescent inpatient must be worked through in psychotherapy. Anyone of emotional significance to the patient, from therapist to kitchen help, can spark an emotional crisis upon departing. Of course the rage reactive to the loss must be articulated. But a genuine mastery over the loss cannot be attained without also articulating the sadness, longing for love, and narcissistic injury that ensue. The rage evoked by deprivation of narcissistic needs is exceedingly difficult to work with, but this rage usually subsides when there is clarification of the aims of these needs. ${ }^{25}$ When narcissistic rage is transformed into object-directed anger, the ego is better able to adapt to and master a loss. When Diane (Case 2) was helped to see how furious she was at her treatment team and her parents for, as she saw it, abandoning her, this tapped a reservoir of rage, which previously had been discharged self-destructively. However, Diane was not able to do much with it other than fulminate unceasingly against parents and staff. When in her therapy she was able to experience her profound sadness about their loss and her affection for them, she was then able to work more constructively on the place both negative and positive feelings played in her experience.

In Diane's therapy much time was spent working through her hurt and rage at her therapist for not protecting her from the painful loss of valued objects and, as she experienced it, for planning to abandon her. It often happens that in therapy, especially with a male therapist, the adolescent girl is helped to reconcile herself to the irretrievable loss of a fantasied close, cuddly little girl attachment to males. The adolescent can tolerate ambivalence in her therapy relationship-able to relate warmly as 
well as to express disappointment and anger. She appears to have given up her oedipal strivings.

For the disturbed adolescents described here, oedipal strivings are not truly faced until the more regressive wish to reunite with and obtain sustenance from the pre-oedipal idealized mother is significantly confronted. This wish often lies behind and fuels oedipal conflicts played out with males. This process certainly was evident in Marilyn's behavior (Case 1). The intensity of her rage over being separated from Frank stemmed from the preoedipal, symbiotic source of those feelings. In psychotherapy the girl, in effect, agrees to forgive the disappointing oedipal father -in the form of her therapist-in return for even greater pleasure: a regressive symbiotic reunion with mother. It is only when this wish is articulated and the fantasied symbiotic tie with mother severed that the adolescent girl is truly able to break the persistent behavioral link between loss and sexual acting-out.

\section{REFERENCES}

1. MoNeil, E. B., and Morse, W. C.: The institutional management of sex in emotionally disturbed children, Am. J. Orthopsychiat., 34: 115-124, 1964.

2. Levy, E. Z.: On the residential treatment of adolescent girls. Seminars on Psychiatry, 1: 3-14, 1969.

3. Miller, D. H.: The Age Between. Cornmarket Hutchinson. London, 1969.

4. Krohn, A., Miller, D. H., and Looney, J.: Flight from autonomy-problems of social change in an adolescent in-patient setting. Psychiatry, 1974 (In press).

5. Easson, W. M.: Adolescent inpatients in love. Arch. Gen. Psychiat., 16: 758 $763,1967$.

6. Papanek, E.: Management of the acting-out adolescent. Am. J. Psychother., $18: 418-434,1964$.

7. Levy, F. Z.: Notes and comments on the sexual behavior of hospitalized adolescents. Presented to the Fortieth Annual Meeting of the National Association of Private Psychiatric Hospitals, January 1973.

8. Blos, P.: The second individuation process of adolescence. Psychoanal. St. Child., 22 : 162-186, 1967.

9. Masterson, J. F.: Treatment of the Borderline Adolescent: A Developmental Approach. Wiley. New York. 1972.

10. Freud, S.: (1917): Mourning and melancholia. Collected Papers, vol. 4. Institute of Psychoanalysis and Hogarth Press. London. 1956.

11. Fleming, J., and Altschul, S.: Activation of mourning and growth by psychoanalysis. Int. J. Psycho-anal., 44 : 419-431, 1963.

12. Pollock, G. H.: Mourning and adaptation. Int. J. Psycho-anal., 42: 341-361, 1961.

13. Bowlby, J.: Processes of mourning. Int. J. Psycho-anal., 42: 317-340, 1961.

14. Shoor, M., and Speed, M. D.: Delinquency as a manifestation of the mourning process. Psychiat. QuART., 37: 540-558, 1968.

15. Blos; P.: Character formation in adolescence. Psychoanal. St. Child, 23: 245-263, 1968. 
16. Sugar, M.: Normal adolescent mourning. Am. J. Psychother., 22: 258-269, 1968.

17. Bowlby, J.: Pathological mourning and childhood mourning. J. Am. Psychoanal. Assn., 11: 500-541, 1963.

18. Laufer, M.: Object Ioss and mourning during adolescence. Psychoanal. St. Child, $21: 269-293,1966$.

19. Deutsch, H.: Absence of grief. Psychoanal. Quart., 6: 12-22, 1937.

20. Wolfenstein, M.: Loss, rage and repetition. Psychoanal. St. Child, 25: 432-460, 1969.

21. Blos, P.: The concept of acting out in relation to the adoleseent process. J. Am. Acad. Child Psychiat., 2: 118-143, 1963.

22. Erikson, E. H.: The problem of ego identity. J. Am. Psychoanal. Assn., 4: 56-121, 1956.

23. Blos, P.: Preoedipal factors in the etiology of female delinquency. Psychoanal. St. Child., 12: 229-249, 1957.

24. Sprince, M. P.: The development of a preoedipal partnership between an adolescent girl and her mother. Psychoanal. St. Child, 17: 419-450, 1962.

25. Kohut, H.: The Analysis of the Self. International Universities Press. New York. 1971. 